\title{
Management of massive retropubic haematoma post-TVT
}

\author{
Lucy May ${ }^{1} \cdot$ Swati Jha $^{1} \cdot$ Shahram Abdi ${ }^{1}$
}

Received: 9 March 2016 / Accepted: 11 April 2016/Published online: 14 May 2016

(C) The Author(s) 2016. This article is published with open access at Springerlink.com

Keywords TVT $\cdot$ Retropubic haematoma

\section{Introduction}

Tension-free vaginal tape (TVT) is well established for the treatment of stress urinary incontinence (SUI), with a cure rate of $84 \%$ [1]. A known complication is the formation of a retropubic haematoma in 1.5-3\% [1] of cases. A massive haematoma is one $>8 \mathrm{~cm}$ and/or a $4 \mathrm{gm} \%$ drop in haemoglobin. Management is often surgical intervention via a laparotomy or observation until spontaneous resolution (Figs 1 and 2).

\section{Case Report}

A 74-year-old patient underwent TVT for SUI. She was discharged home the next day but presented with pain,

Swati Jha

swatijha83@hotmail.com

1 Department of Urogynaecology, Jessop Wing, Sheffield Teaching Hospitals, Sheffield S10 2SF, UK urgency and persistent urinary leakage 1 week later. On review, the wound was healing normally but an ultrasound (US) scan revealed a 9-cm organising haematoma. She underwent US-guided drainage of the haematoma, and a size 12-F locking drain was inserted and left on free drainage for $48 \mathrm{~h}$; this was flushed twice daily to prevent blockage. On day 2 , the drain was removed; $200 \mathrm{ml}$ of blood was drained. Repeat US 4 weeks later showed the collection to be halved, with a diameter of $5 \mathrm{~cm}$ and complete symptom resolution (Figs 1 and 2).

Although not a common complication after a TVT, massive retropubic haematomas can be life threatening due to significant blood loss. A review of the literature demonstrates surgical drainage via a laparotomy in most cases. One study identified 2,091 patients over a 15-year period who underwent a midurethral sling procedure, seven of whom developed a haematoma, with six requiring surgical intervention either by laparotomy, vaginal drainage or suprapubic drainage [2]. Retziusscopy has also been reported as a management technique for haematomas after a TVT [3].

This case demonstrates that US-guided drainage can be an effective treatment for massive retropubic haematomas in stable patients, providing good recovery of bladder function. It avoids repeat anaesthetic and further surgery and therefore is a safe approach. 
Fig. 1 Predrainage transvaginal ultrasound scan of

haematoma $=9 \mathrm{~cm}$ (ultrasound depth $8.1 \mathrm{~cm}$ )
Fig. 2 Predrainage transvaginal ultrasound scan of haematoma $=5 \mathrm{~cm}$ (ultrasound depth $7.1 \mathrm{~cm}$, making haematoma more magnified)
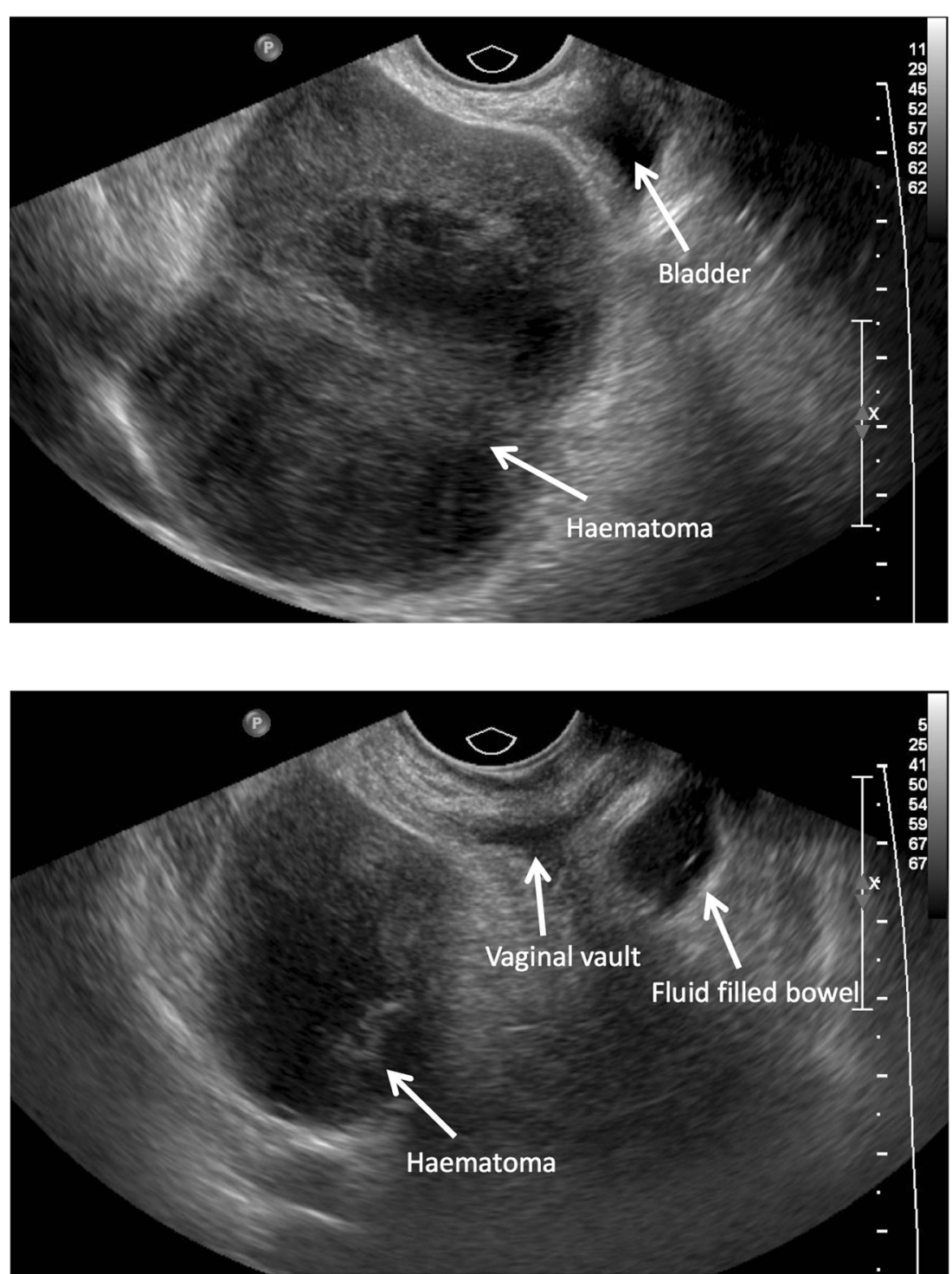

\section{Compliance with ethical standards}

\section{Conflict of Interest None.}

Consent Written informed consent was obtained from the patient for publication of this Images in Urogynecology and any accompanying images.

Open Access This article is distributed under the terms of the Creative Commons Attribution 4.0 International License (http:// creativecommons.org/licenses/by/4.0/), which permits unrestricted use, distribution, and reproduction in any medium, provided you give appropriate credit to the original author(s) and the source, provide a link to the Creative Commons license, and indicate if changes were made.

\section{References}

1. Boustead GB (2002) The tension-free vaginal tape for treating female stress urinary incontinence. BJU 89(7):687-693

2. Balachandran A, Curtiss N, Duckett J (2015) The management of massive haematomas after insertion of retropubic mid-urethral slings. Int Urogynecol J 26(10):1449-1452

3. Flock F, Kohorst F, Kreienberg R, Reich A (2011) Retziusscopy: a minimal invasive technique for the treatment of retropubic hematomas after TVT procedure. EJOGRB 158(1):101-103 